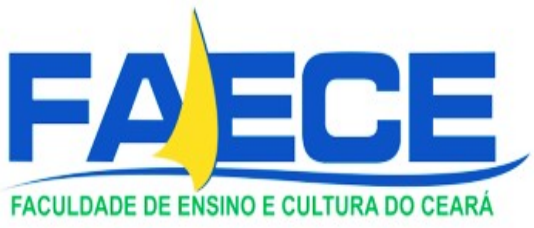

FACULDADE DE ENSINO E CULTURA DO CEARÁ - FAECE CURSO DE GRADUAÇÃO EM ENFERMAGEM

MARIA AMANDA OLIVEIRA DA SILVA

INSTRUMENTOS DE AVALIAÇÃO DA DEPRESSÃO UTILIZADOS NA PRÁTICA CLÍNICA DE ENFERMAGEM: REVISÃO NARRATIVA DA LITERATURA

FORTALEZA - CEARÁ 
INSTRUMENTOS DE AVALIAÇÃO DA DEPRESSÃO UTILIZADOS NA PRÁTICA CLÍNICA DE ENFERMAGEM: REVISÃO NARRATIVA DA LITERATURA

Trabalho de Conclusão de Curso apresentado ao Curso de Graduação em Enfermagem da Faculdade de Ensino e Cultura do Ceará (FAECE), como requisito parcial à obtenção do título de Bacharel em Enfermagem.

Orientadora: Profa. Ms. Fernanda Rochelly do Nascimento Mota. 


\section{INSTRUMENTOS DE AVALIAÇÃO DA DEPRESSÃO UTILIZADOS NA PRÁTICA CLÍNICA DE ENFERMAGEM: REVISÃO NARRATIVA DA LITERATURA}

Trabalho de Conclusão de Curso apresentado ao Curso de Graduação em Enfermagem da Faculdade de Ensino e Cultura do Ceará (FAECE), como requisito parcial à obtenção do título de Bacharel em Enfermagem.

BANCA EXAMINADORA:

Profa. Ms. Fernanda Rochelly do Nascimento Mota (Orientadora) (Faculdade de Ensino do Ceará - FAECE)

Profa. Dra. Stella Maia Barbosa ( $1^{\circ}$ Membro)

(Faculdade de Ensino do Ceará - FAECE)

Enfa ${ }^{a}$ Esp. Carolina Sharlene Miranda Sampaio ( $2^{\circ}$ Membro)

(Faculdade de Ensino do Ceará - FAECE)

FORTALEZA - CEARÁ 


\section{AGRADECIMENTOS}

Primeiramente a Deus, por me dar coragem e disposição para lutar por meus sonhos. A vida nem sempre é fácil ou do jeito que gostaríamos que fosse, ela as vezes é dura e como diz minha orientadora Fernanda Rochelly temos que ser mais duro ainda, para alcançar algo temos que superar os obstáculos. Deus sabe o quanto batalhei e me reinventei para chegar ate aqui, no decorrer do percurso virei mãe, esposa e amadureci bastante. Espero concretizar mais coisas na minha jornada. Desde já me sinto realizada.

Ao meu filho Kayke, que apesar de ser ainda um bebê já me dar força da qual não tem explicações, ser mãe e saber que tem alguém que faz parte de você é algo gratificante, apesar de muitas vezes me sentir tão cansada para dividir meu tempo entre tantas tarefas já me sinto de fato guerreira.

A minha mãe por ser um exemplo de humildade e gentileza da qual sempre me apoiou em tudo, esteve do meu lado em todos os momentos bons e ruins, dedicou seu tempo ao meu filho para me apoiar a continuar meus estudos, me ensinou que de uma simples pedra podemos fazer degraus de vitória.

Meu pai homem forte e obstinado do qual sempre ensinou a seus filhos que na vida além de caráter é importante estudar para ser algo na vida.

A meu esposo, do qual sempre me apoiou nos estudos sempre me fez me sentir alguém importante alguém independente que além de bom marido, é um ótimo pai, ele é um exemplo de que apesar de haver inúmeras barreiras no caminho ainda podemos sorrir no final. 


\section{RESUMO}

A depressão é caracterizada como um distúrbio afetivo que pode provocar alterações mentais, corporais e alterações de humor, da qual muitas vezes passa despercebida, ou é vista de maneira errônea, retardando assim o seu diagnóstico. Objetivou-se investigar, na literatura científica nacional, quais os instrumentos de avaliação da depressão disponíveis na prática clínica do enfermeiro. Trata-se de um estudo descritivo, do tipo revisão narrativa da literatura. Os dados foram coletados através das Bases de Dados BDENF, ADOLEC e LILACS, no mês de outubro de 2018, a fim de responder à questão norteadora da revisão: "Quais os instrumentos de avaliação da depressão disponíveis para utilização pelo enfermeiro em sua prática clínica?" Verificou-se que, acerca dos instrumentos de avaliação da depressão utilizados na prática clínica de enfermagem, tem-se um público muito abrangente em relação à aplicação dos instrumentos: idosos, profissionais de saúde, pacientes adultos com problemas clínicos específicos, acadêmicos de Enfermagem, gestantes e puérperas. Foram identificados sete instrumentos: Escala de depressão geriátrica de Yesavage, Inventario de depressão de Beck, Escala de depressão de Edimburgo, Escala de avaliação para depressão de Hamilton, Montgomery-Asberg Depression Rating Scale, Escala hospitalar de ansiedade e depressão, e a escala short-care, que integra o instrumento de avaliação multidimensional BOAS (Brazil Old Age Schedule). De acordo com a literatura científica nacional, concluiu-se que o enfermeiro tem um papel fundamental no conhecimento e aplicação dos instrumentos, pois o mesmo poderá atuar na promoção de saúde prevenindo possíveis fatores causais relacionados à depressão. Pode se entender que na prática clínica do enfermeiro há vários instrumentos que possibilitam um trabalho mais amplo evidenciando melhores resultados para o profissional e para o paciente pois o mesmo estará ciente a respeito dos possíveis fatores de riscos que podem prejudicar a saúde, facilitando seu trabalho para uma melhor elaboração de estratégias em saúde.

Palavras-chave: Depressão. Instrumentos de avaliação. Enfermagem. 


\begin{abstract}
Depression is characterized as an affective disorder that can cause mental changes, bodily changes and mood swings, which often goes unnoticed or is mistakenly seen, thus delaying its diagnosis. The objective was to investigate, in the national scientific literature, the instruments of evaluation of depression available in the clinical practice of the nurse. It is a descriptive study, of the type narrative review of the literature. The data were collected through the databases BDENF, ADOLEC and LILACS, in the month of October 2018, in order to answer the guiding question of the review: "What are the evaluation instruments of depression available for use by the nurse in his clinical practice? "It has been verified that, regarding the instruments of evaluation of depression used in clinical nursing practice, there is a very wide public regarding the application of the instruments: elderly, health professionals, adult patients with specific clinical problems, Nursing academics, pregnant women and puerperal women. Seven instruments were identified: Yesavage Geriatric Depression Scale, Beck Depression Inventory, Edinburgh Depression Scale, Hamilton Depression Rating Scale, Montgomery-Asberg Depression Rating Scale, Hospital Scale of Anxiety and Depression, and Short Scale -care, which integrates the BOAS (Brazil Old Age Schedule) multidimensional assessment tool. According to the national scientific literature, it was concluded that nurses have a fundamental role in the knowledge and application of the instruments, since it can act in the promotion of health preventing possible causal factors related to depression. It can be understood that in the clinical practice of the nurse there are several instruments that allow a broader work showing better results for the professional and the patient since the patient will be aware of the possible risk factors that can harm health, facilitating their work to development of health strategies.
\end{abstract}

Keywords: Depression. Instruments of evaluation. Nursing. 


\section{LISTA DE QUADROS}

Quadro 1 - Caracterização da amostra (artigos incluídos na revisão narrativa) baseada no instrumento/ escala geriátrica de Yesavage

Quadro 2 - Caracterização da amostra (artigos incluídos na revisão narrativa) baseada no Inventário de depressão de Beck 16

Quadro 3 - Caracterização da amostra (artigos incluídos na revisão narrativa) baseada na Escala de depressão de Edinburgo .

Quadro 4 - Caracterização da amostra (artigos incluídos na revisão narrativa) baseada na Escala de avaliação para depressão Hamilton

Quadro 5 - Caracterização da amostra (artigos incluídos na revisão narrativa) baseada na Escala de avaliação para depressão de Montgomery - Asberg Depression Rating Scale

Quadro 6 - Caracterização da amostra (artigos incluídos na revisão narrativa) baseada na Escala hospitalar de ansiedade e depressão

Quadro 7 - Caracterização da amostra (artigos incluídos na revisão narrativa) baseada na Escala short-care que integra $O$ instrumento de avaliação multidimensional BOAS

Quadro 8 - Caracterização da amostra (artigos incluídos na revisão narrativa) conforme descrição 
SUMÁRIO

1 INTRODUÇÃO

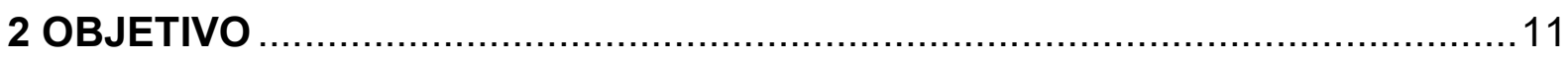

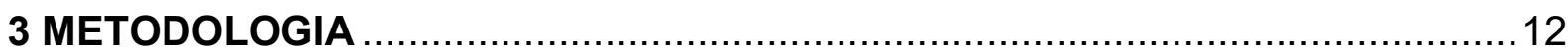

4 RESULTADOS E DISCUSSÃO

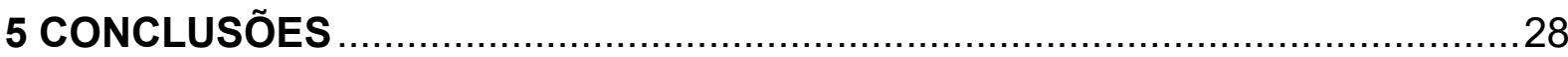

REFERÊNCIAS 


\section{INTRODUÇÃO}

A depressão é caracterizada como um distúrbio afetivo que pode provocar alterações mentais, corporais e alterações de humor, e muitas vezes passam despercebidas, ou é vista de maneira errônea, retardando assim o seu diagnóstico (NOBREGA et al, 2015).

Outros aspectos ligados à depressão são a perda de interesse e prazer em quase todas as atividades diárias, alterações no apetite, peso, sono e convívio social, prejudicando assim o estilo de vida da pessoa (LOPES et al,2015).

Sabe-se que a depressão é um problema de saúde pública que vem atingindo mundialmente milhões de pessoas, e também está associado o gênero, idade e estado civil. A vulnerabilidade entre as pessoas idosas, por exemplo, pode ser decorrente de problemas de saúde e alterações de humor, nesse aspecto foi visto que esta é a população que vem sendo mais atingida predominando o sexo feminino (LOPES et al,2015).

Atualmente estudos mostram que pessoas com a faixa etária entre 65 anos ou mais são acometidas pela depressão. Já no Brasil o público com essa mesma faixa etária "São de 14,5 milhões de pessoas, correspondendo a $8,6 \%$ do total da população do país, com projeção para 9,7\% em 2050" (LIMA et al, 2016).

Os instrumentos que avaliam a depressão, como o próprio nome já cita, servem para estabelecer possíveis fatores e causas depressivas, proporcionando assim uma maior efetividade e promoção à saúde, por exemplo: A escala de Hamilton ela serve para analisar e identificar a gravidade dos sintomas depressivos, e não a sua existência, investigando como o paciente tem se sentido nos últimos sete dias, incluindo o dia da aplicação (FREIRE, et al., 2014).

É importante ressaltar que os instrumentos que avaliam a depressão ajudam de maneira efetiva a investigar relação desta doença com fatores de riscos associados, favorecendo o desenvolvimento de estratégias que minimizem a prevalência de sintomas e facilitando o diagnóstico e a mensuração da gravidade de cada caso.

Nesse contexto, o enfermeiro é um agente primordial, pois tendo conhecimentos acerca dos instrumentos de avaliação de depressão que podem ser utilizados no cenário assistencial, bem como com a destreza quanto à correta aplicação desses instrumentos, poderá empregá-los de maneira efetiva em sua 
prática profissional, traçar estratégias oportunas para à promoção da saúde mental dos diferentes públicos assistidos, utilizar na prevenção de possíveis fatores causais da doença. 
2 OBJETIVO

Investigar, na literatura científica nacional, quais os instrumentos de avaliação da depressão disponíveis para a prática clínica do enfermeiro. 


\section{METODOLOGIA}

Trata-se de um estudo descritivo, do tipo revisão narrativa da literatura. Esse tipo de estudo é baseado na apresentação de informações recentes, podendo utilizar fontes de informações bibliográficas ou eletrônicas, possibilitando conhecimentos atualizados sobre o tema pesquisado, e assim destacando lacunas no corpo de pesquisas, levando pesquisadores a aprimorar dados científicos sobre $o$ assunto definido (ROTHER, 2007).

Realizaram-se buscas nas Bases de Dados BDENF, ADOLEC e LILACS, no mês de outubro de 2018, a fim de responder a questão norteadora da revisão: "Quais os instrumentos de avaliação da depressão disponíveis para utilização pelo enfermeiro em sua prática clínica?".

Os descritores: "Depressão" AND "Enfermagem" (DeCS - Descritores em Ciências da Saúde) foram empregados nas buscas." Os critérios de inclusão foram: documentos do tipo artigo científico, identificados nas bases de dados eleitas para o estudo, com texto completo gratuitamente disponível para download, no idioma português, publicados entre os anos 2013 e 2018. Optou-se por esse período pelo fato de pretender-se identificar os conhecimentos científicos mais atuais acerca de instrumentos existentes para avaliação da depressão que podem ser usados na prática clínica de enfermeiros brasileiros. Excluíram-se editoriais, textos acadêmicos (teses, dissertações, monografias), bem como documentos repetidos.

No BDENF, a busca revelou o total de 245 títulos encontrados, onde foram selecionados 12 artigos do ano de 2013 a 2018, sendo que três (03) eram repetidos da base de dados LILACS, outros três (03) artigos não estavam no idioma português. Assim, após leitura dos textos completos, restaram seis (06) artigos, que foram incluídos na amostra.

No LILACS, a busca inicial revelou o total de 301 títulos com textos completos disponíveis, utilizando-se os descritores "depressão" e "enfermagem". Destes, 185 publicações no idioma português. Após selecionar os títulos de artigos científicos, restaram 164. Destes, 77 foram publicados entre os anos 2013 a 2018. Feita a leitura de títulos e resumos dos 77 , foram selecionados 22 artigos para a revisão; porém, com a leitura dos textos completos, quatro títulos foram excluídos por não responderem a questão norteadora da investigação. Desta forma, 18 artigos do LILACS foram incluídos na amostra final da revisão narrativa. 
No ADOLEC, a busca revelou o total de 28 artigos científicos com textos completos. Destes, apenas um (01) foi selecionado para integrar a amostra final da revisão, considerando-se os critérios de inclusão: ano de publicação e resposta á questão norteadora.

Após seleção da amostra final de 25 artigos científicos, estes foram lidos na íntegra, organizados em quadros para a coleta e apresentação de informações, e analisados descritivamente de acordo com o objetivo da revisão.

A Figura 1, abaixo, apresenta o fluxograma do processo de seleção dos estudos da revisão narrativa da literatura para identificação dos instrumentos de avaliação da depressão utilizados na prática clínica do enfermeiro. 
FIGURA 1- Fluxograma do processo de seleção dos estudos para a revisão narrativa da literatura Fortaleza - Ceará - Brasil, 2018

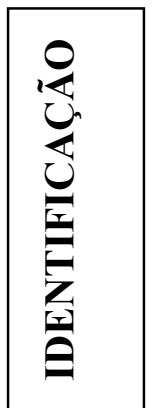

Referências identificadas através da busca nas bases de dados BDENF (245 artigos) ADOLEC (28 artigos) e LILACS (301 artigos).

Total $=574$ artigos

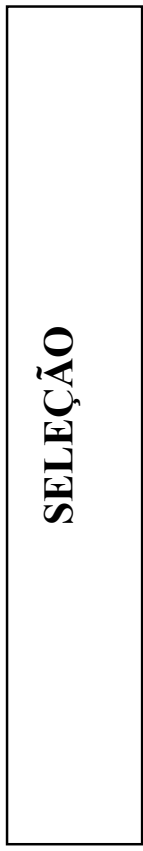

BDENF do ano 2013 a 2018 - 12 artigos

LILACS no idioma português - 185 artigos

Apenas títulos científicos - 164 artigos

Publicados entre os anos 2013 a 2018 - 77 artigos

Incluídos na amostra final 18 artigos

ADOLEC do ano 2013 a 2018 e respondendo a questão norteadora 1 artigo

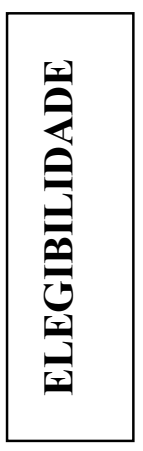

Artigos completos analisados:

LILACS - 18 artigos

BDENF - 06 artigos

ADOLEC - 01 artigos

TOTAL: 25 artigos

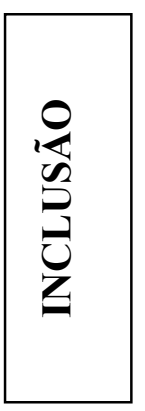

Artigos incluídos na síntese:

25 artigos

Fonte: elaboração própria. 


\section{RESULTADOS E DISCUSSÃO}

Verificou-se que, acerca dos instrumentos de avaliação da depressão utilizados na prática clínica de enfermagem, tem-se um público muito abrangente em relação á aplicação dos instrumentos: idosos, profissionais de saúde, pacientes adultos com problemas clínicos específicos, acadêmicos de Enfermagem, gestantes e puérperas.

O ano identificado com mais publicações sobre o assunto foi 2014, com sete artigos. O quadro 1 , abaixo, mostra, em relação aos artigos da amostra: os títulos, autores, ano de publicação, objetivos da pesquisa, tipo de estudo e quais os instrumentos de avaliação da depressão utilizados nos estudos.

Quadro 1 - Caracterização da amostra (artigos incluídos na revisão narrativa) baseada no instrumento/ escala geriátrica de Yesavage

\begin{tabular}{|c|c|c|c|c|}
\hline Título & $\begin{array}{l}\text { Autores e ano } \\
\text { de publicação }\end{array}$ & $\begin{array}{c}\text { Principal (ais) } \\
\text { objetivo(s) }\end{array}$ & $\begin{array}{l}\text { Tipo de } \\
\text { estudo }\end{array}$ & $\begin{array}{c}\text { Instrumento } \\
\text { escala } \\
\text { geriátrica de } \\
\text { Yesavage }\end{array}$ \\
\hline $\begin{array}{lr}\text { Aplicação } & \text { da } \\
\text { escala } & \text { de } \\
\text { depressão } & \\
\text { geriátrica } & \text { de } \\
\text { Yesavage } & \text { em } \\
\text { instituições } & \text { de } \\
\text { longa permanência. }\end{array}$ & $\begin{array}{l}\text { (FREIRE, et al., } \\
\text { 2018) }\end{array}$ & $\begin{array}{lr}\text { Identificar } & \text { a } \\
\text { prevalência de } & \text { depressão em } \\
\text { didosos residentes } \\
\text { em instituições de } \\
\text { longa permanecia. }\end{array}$ & $\begin{array}{l}\text { Pesquisa } \\
\text { exploratória, } \\
\text { de abordagem } \\
\text { quantitativa. }\end{array}$ & $\begin{array}{ll}\text { Escala } & \text { de } \\
\text { depressão } & \\
\text { geriátrica. } & \end{array}$ \\
\hline $\begin{array}{l}\text { Perfil } \\
\text { sociodemográfico, } \\
\text { aspectos familiares, } \\
\text { percepção de } \\
\text { saúde, capacidade } \\
\text { funcional } \\
\text { depressão em } \\
\text { idosos } \\
\text { institucionalizados } \\
\text { no litoral norte do } \\
\text { Rio Grande do Sul, } \\
\text { Brasil. }\end{array}$ & $\begin{array}{l}\text { (GUTHS, et al., } \\
2017)\end{array}$ & $\begin{array}{l}\text { Descrever } \\
\text { características } \\
\text { sociodemográficas, } \\
\text { familiares, situação } \\
\text { de saúde, } \\
\text { depressão e grau } \\
\text { de capacidade } \\
\text { funcional em idosos } \\
\text { institucionalizados. }\end{array}$ & $\begin{array}{l}\text { Estudo } \\
\text { descritivo } \\
\text { transversal. }\end{array}$ & $\begin{array}{l}\text { Escala } \\
\text { depressão } \\
\text { geriátrica. }\end{array}$ \\
\hline $\begin{array}{l}\text { Avaliação cognitiva } \\
\text { e funcional de } \\
\text { idosos usuários do } \\
\text { serviço público de } \\
\text { saúde. }\end{array}$ & $\begin{array}{l}\text { (MELO, et al., } \\
2017)\end{array}$ & $\begin{array}{l}\text { Avaliar } \\
\text { capacidade } \\
\text { funcional, cognitiva } \\
\text { e humor em três } \\
\text { diferentes modelos } \\
\text { de atenção ao } \\
\text { idoso. }\end{array}$ & $\begin{array}{l}\text { Estudo } \\
\text { seccional, } \\
\text { comparativo. }\end{array}$ & $\begin{array}{l}\text { Escala } \\
\text { depressão } \\
\text { geriátrica. }\end{array}$ \\
\hline
\end{tabular}


Quadro 1 - Caracterização da amostra (artigos incluídos na revisão narrativa) baseada no instrumento/ escala geriátrica de Yesavage, continuação

\begin{tabular}{|c|c|c|c|c|}
\hline $\begin{array}{l}\text { Prevalência de } \\
\text { sintomatologia } \\
\text { depressiva e } \\
\text { fatores associados } \\
\text { entre idosos } \\
\text { institucionalizados. }\end{array}$ & $\begin{array}{lll}\text { (LEAL et al., } \\
2014)\end{array}$ & $\begin{array}{lr}\text { Conhecer } & \text { a } \\
\text { prevalência da } \\
\text { sintomatologia } \\
\text { depressiva e } \\
\text { fatores associados } \\
\text { em idosos } \\
\text { institucionalizados. }\end{array}$ & $\begin{array}{l}\text { Estudo } \\
\text { transversal, } \\
\text { quantitativo. }\end{array}$ & $\begin{array}{l}\text { Escala } \\
\text { depressão } \\
\text { geriátrica. }\end{array}$ \\
\hline $\begin{array}{l}\text { Perfil } \\
\text { sociodemográfico, } \\
\text { econômico e de } \\
\text { saúde de idosos } \\
\text { rurais segundo o } \\
\text { indicativo de } \\
\text { depressão. }\end{array}$ & $\begin{array}{l}\text { (RODRIGUES et } \\
\text { al., 2014) }\end{array}$ & $\begin{array}{lr}\text { Comparar } & \text { as } \\
\text { variáveis } \\
\text { sociodemográfico, } \\
\text { econômicas } \\
\text { percepção } \\
\text { saúde de } \\
\text { idosos residentes } \\
\text { na zona rural, } \\
\text { divididos em dois } \\
\text { grupos }\end{array}$ & $\begin{array}{l}\text { Estudo analítico, } \\
\text { transversal } \\
\text { observacional. }\end{array}$ & $\begin{array}{l}\text { Escala } \\
\text { depressão } \\
\text { geriátrica. }\end{array}$ \\
\hline $\begin{array}{l}\text { Depressão e bem- } \\
\text { estar em individuo } \\
\text { idoso com ulcera } \\
\text { venoso. }\end{array}$ & $\begin{array}{l}\text { (PEREIRA et al., } \\
2014)\end{array}$ & $\begin{array}{lr}\text { Avaliar } & \text { bem-estar } \\
\text { subjetivo } & \text { e } \\
\text { depressão } & \text { em } \\
\text { pessoas } & \text { idosas } \\
\text { com } & \text { úlcera } \\
\text { venosa. } & \\
\end{array}$ & $\begin{array}{l}\text { Estudo clínico, } \\
\text { primário, } \\
\text { descritivo, } \\
\text { analítico } \\
\text { multicêntrico. }\end{array}$ & $\begin{array}{l}\text { Escala } \\
\text { depressão } \\
\text { geriátrica }\end{array}$ \\
\hline $\begin{array}{l}\text { Características } \\
\text { sociodemográfico } \\
\text { e hábitos de vida } \\
\text { de idosos com e } \\
\text { sem indicativo de } \\
\text { depressão. }\end{array}$ & $\begin{array}{l}\text { (FERREIRA et } \\
\text { al., 2013) }\end{array}$ & $\begin{array}{l}\text { Comparar as } \\
\text { variáveis } \\
\text { sociodemográfico } \\
\text { e hábitos de vida } \\
\text { dos idosos com e } \\
\text { sem indicativo de } \\
\text { depressão }\end{array}$ & $\begin{array}{l}\text { Estudo descritivo, } \\
\text { transversal } \\
\text { observacional. }\end{array}$ & $\begin{array}{l}\text { Escala } \\
\text { depressão } \\
\text { geriátrica }\end{array}$ \\
\hline
\end{tabular}

Fonte: elaboração própria.

Quadro 2 - Caracterização da amostra (artigos incluídos na revisão narrativa) baseada no Inventário de depressão de Beck

\begin{tabular}{|c|c|c|c|c|}
\hline Título & $\begin{array}{l}\text { Autores e ano } \\
\text { de publicação }\end{array}$ & $\begin{array}{c}\text { Principal (ais) } \\
\text { objetivo(s) }\end{array}$ & Tipo de estudo & $\begin{array}{c}\text { Inventario de } \\
\text { depressão de } \\
\text { Beck }\end{array}$ \\
\hline $\begin{array}{l}\text { Depressão } \mathrm{e} \\
\text { qualidade de vida } \\
\text { em adultos com } \\
\text { hipertensão. }\end{array}$ & $\begin{array}{l}\text { (MANTOVANI, et } \\
\text { al., 2017) }\end{array}$ & $\begin{array}{lr}\text { Investigar } & \text { a } \\
\text { relação } & \text { entre } \\
\text { depressão } & \text { e } \\
\text { qualidade de vida } \\
\text { em adultos } & \text { com } \\
\text { hipertensão } & \\
\text { arterial sistêmica. }\end{array}$ & $\begin{array}{l}\text { Pesquisa } \\
\text { quantitativa, com } \\
\text { delineamento } \\
\text { transversal. }\end{array}$ & $\begin{array}{ll}\text { Inventario } & \text { de } \\
\text { Depressão } & \text { de } \\
\text { Beck. } & \end{array}$ \\
\hline
\end{tabular}


Quadro 2 - Caracterização da amostra (artigos incluídos na revisão narrativa) baseada no Inventário de depressão de Beck, continuação

\begin{tabular}{|c|c|c|c|c|}
\hline $\begin{array}{l}\text { Alterações } \\
\text { cognitivas em } \\
\text { enfermeiros que } \\
\text { atuam em unidade } \\
\text { de terapia } \\
\text { intensiva. }\end{array}$ & $\begin{array}{l}\text { (MACHADO et } \\
\text { al., 2016) }\end{array}$ & $\begin{array}{l}\text { Medir os níveis de } \\
\text { estresse, } \\
\text { ansiedade, } \\
\text { depressão dos } \\
\text { enfermeiros que } \\
\text { atuam em UTI. }\end{array}$ & $\begin{array}{l}\text { Estudo } \\
\text { observacional } \\
\text { analítico, } \\
\text { quantitativo. }\end{array}$ & $\begin{array}{l}\text { Inventario } \\
\text { Depressão } \\
\text { Beck. }\end{array}$ \\
\hline $\begin{array}{l}\text { Burnout } \\
\text { sintomatologia } \\
\text { depressiva em } \\
\text { enfermeiros de } \\
\text { terapia intensiva: } \\
\text { analise de relação. }\end{array}$ & $\begin{array}{l}\text { (VASCONCELOS } \\
\text { et al., 2016) }\end{array}$ & $\begin{array}{lr}\text { Analisar } & \text { a } \\
\text { existência } & \text { de } \\
\text { relação entre o } & \text { a } \\
\text { burnout e a } & \text { sintomatologia } \\
\text { depressiva } & \text { em } \\
\text { enfermeiros de } \\
\text { unidade de terapia } \\
\text { intensiva. }\end{array}$ & $\begin{array}{l}\text { Estudo } \\
\text { quantitativo, } \\
\text { descritivo, } \\
\text { transversal. }\end{array}$ & $\begin{array}{l}\text { Inventario } \\
\text { Depressão } \\
\text { Beck. }\end{array}$ \\
\hline $\begin{array}{l}\text { Stress burnout e } \\
\text { avaliação } \\
\text { cognitiva: estudo } \\
\text { na classe de } \\
\text { enfermagem. }\end{array}$ & $\begin{array}{l}\text { (PEREIRA; } \\
\text { GOMES, 2016) }\end{array}$ & $\begin{array}{lr}\begin{array}{lr}\text { Analisar o } \\
\text { laboral }\end{array} & \begin{array}{r}\text { stress } \\
\text { enfermeiros, }\end{array} \\
\text { observando } & \\
\text { igualmente } & \text { a } \\
\text { importância } & \text { dos } \\
\text { processos. } & \end{array}$ & $\begin{array}{l}\text { Estudo descritivo, } \\
\text { correlacional. }\end{array}$ & $\begin{array}{l}\text { Inventario } \\
\text { depressão } \\
\text { Beck. }\end{array}$ \\
\hline $\begin{array}{ll}\text { Desemprego } & \text { e } \\
\text { sofrimento } & \\
\text { psíquico } & \text { em } \\
\text { enfermeiras. } & \end{array}$ & $\begin{array}{l}\text { (SILVA; } \\
\text { MARCOLAN, } \\
2015)\end{array}$ & $\begin{array}{lr}\text { Verificar } & 0 \\
\text { sofrimento } & \\
\text { psíquico } & \text { em } \\
\text { enfermeiros } & \text { na } \\
\text { busca do primeiro } \\
\text { emprego }\end{array}$ & $\begin{array}{l}\text { Pesquisa } \\
\text { qualitativa, } \\
\text { descritiva. }\end{array}$ & $\begin{array}{l}\text { Inventario } \\
\text { depressão } \\
\text { Beck. }\end{array}$ \\
\hline $\begin{array}{l}\text { Sintomas de } \\
\text { depressão } \\
\text { fatores } \\
\text { intervenientes } \\
\text { entre enfermeiros } \\
\text { de serviço } \\
\text { hospitalar de } \\
\text { emergência. }\end{array}$ & $\begin{array}{l}\text { (OLIVEIRA; } \\
\text { MAZZAIA; } \\
\text { MARCOLAN, } \\
\text { 2014) }\end{array}$ & 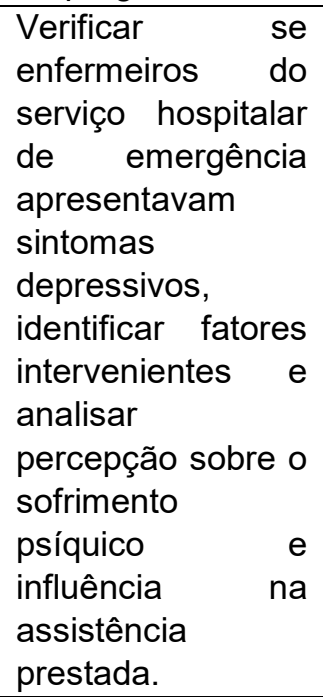 & $\begin{array}{l}\text { Estudo } \\
\text { transversal, } \\
\text { quantitativo. }\end{array}$ & $\begin{array}{lr}\text { Inventario } & \text { de } \\
\text { depressão } & \text { Beck, } \\
\text { Escala } & \text { de } \\
\text { avaliação } & \text { de } \\
\text { depressão } & \\
\text { Hamilton } & \text { e } \\
\text { Montgomery- } & \\
\text { Asberg } & \\
\text { Depression } & \\
\text { Rating Scale. }\end{array}$ \\
\hline
\end{tabular}


Quadro 2 - Caracterização da amostra (artigos incluídos na revisão narrativa) baseada no Inventário de depressão de Beck, continuação

\begin{tabular}{|c|c|c|c|c|}
\hline $\begin{array}{lr}\text { Prevalência } & \text { de } \\
\text { casos } & \text { de } \\
\text { depressão } & \text { em } \\
\text { acadêmicos } & \text { de } \\
\text { enfermagem } & \text { em } \\
\text { uma instituição de } & \\
\text { ensino de Brasília. }\end{array}$ & $\begin{array}{l}\text { (CAMARGO; } \\
\text { SOUSA; } \\
\text { OLIVEIRA, 2014) }\end{array}$ & 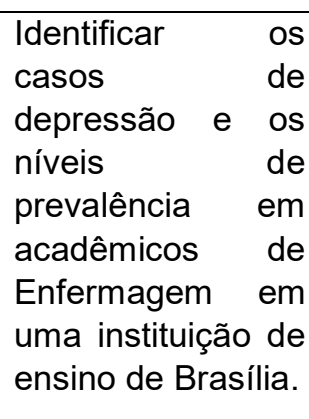 & $\begin{array}{l}\text { Estudo } \\
\text { exploratório } \\
\text { descritivo, } \\
\text { quantitativo. }\end{array}$ & $\begin{array}{l}\text { Inventario de } \\
\text { depressão Beck }\end{array}$ \\
\hline $\begin{array}{lr}\text { Avaliação } & \text { da } \\
\text { presença } & \text { de } \\
\text { sintomas } & \\
\text { depressivos } & \text { entre } \\
\text { usuários } & \text { de } \\
\text { plantão noturno } \\
\text { em unidade de } \\
\text { emergência. }\end{array}$ & $\begin{array}{l}\text { (SANTOS; } \\
\text { FUREGATO, } \\
\text { 2013) }\end{array}$ & 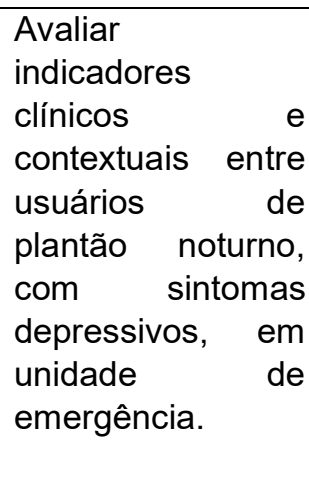 & $\begin{array}{l}\text { Estudo descritivo, } \\
\text { exploratório, } \\
\text { transversal. }\end{array}$ & $\begin{array}{l}\text { Inventario de } \\
\text { depressão Beck. }\end{array}$ \\
\hline $\begin{array}{l}\text { Depressão, } \\
\text { ansiedade } \\
\text { suporte social em } \\
\text { profissionais de } \\
\text { enfermagem. }\end{array}$ & $\begin{array}{l}\text { (GOMES; } \\
\text { OLIVEIRA, 2013) }\end{array}$ & $\begin{array}{lr}\text { Investiga } & \text { a } \\
\text { correlação } & \text { entre } \\
\text { depressão } & \text { e } \\
\text { ansiedade } & \text { e } \\
\text { percepção } & \text { de } \\
\text { suporte social } & \text { em } \\
\text { 39 profissionais de } \\
\text { enfermagem. }\end{array}$ & $\begin{array}{l}\text { Estudo } \\
\text { transversal, } \\
\text { quantitativo. }\end{array}$ & $\begin{array}{l}\text { Inventario de } \\
\text { depressão Beck. }\end{array}$ \\
\hline $\begin{array}{l}\text { Adoecimento } \\
\text { psíquico de } \\
\text { trabalhadores de } \\
\text { unidades de } \\
\text { terapia intensiva. }\end{array}$ & $\begin{array}{l}\text { (MONTEIRO et } \\
\text { al., 2013) }\end{array}$ & $\begin{array}{lr}\text { Compreender } & \\
\text { aspectos } & \text { da } \\
\text { organização } & \text { do } \\
\text { trabalho } & \text { que } \\
\text { podem } & \text { estar } \\
\text { associados } & \text { ao } \\
\text { adoecimento } & \\
\text { psíquico. } & \end{array}$ & $\begin{array}{l}\text { Estudo descritivo, } \\
\text { com } \\
\text { delineamento de } \\
\text { método misto. }\end{array}$ & $\begin{array}{l}\text { Inventario } \\
\text { depressão } \\
\text { Beck. }\end{array}$ \\
\hline $\begin{array}{lr}\text { Estresse } & \text { e } \\
\text { depressão entre } & \\
\text { alunos do último } \\
\text { período de dois } \\
\text { cursos } \\
\text { enfermagem. }\end{array}$ & $\begin{array}{l}\text { (MOREIRA; } \\
\text { FUREGATO, } \\
\text { 2013) }\end{array}$ & $\begin{array}{lr}\text { Identificar } & \text { a } \\
\text { presença } & \text { de } \\
\text { estresse } & \text { e } \\
\text { depressão } & \text { entre } \\
\text { estudantes } & \text { do } \\
\text { último ano de dois } \\
\text { cursos } & \text { de } \\
\text { enfermagem. }\end{array}$ & $\begin{array}{l}\text { Estudo } \\
\text { exploratório } \\
\text { descritivo, } \\
\text { quantitativo. }\end{array}$ & $\begin{array}{l}\text { Inventário } \\
\text { depressão } \\
\text { Beck. }\end{array}$ \\
\hline
\end{tabular}

Fonte: elaboração própria. 
Quadro 3 - Caracterização da amostra (artigos incluídos na revisão narrativa) baseada na Escala de depressão de Edinburgo

\begin{tabular}{|c|c|c|c|c|}
\hline Título & $\begin{array}{l}\text { Autores e ano } \\
\text { de publicação }\end{array}$ & $\begin{array}{c}\text { Principal (ais) } \\
\text { objetivo(s) }\end{array}$ & $\begin{array}{l}\text { Tipo de } \\
\text { estudo }\end{array}$ & $\begin{array}{c}\text { Escala de } \\
\text { depressão de } \\
\text { Edinburgh }\end{array}$ \\
\hline $\begin{array}{l}\text { Sintomas } \\
\text { depressivos na } \\
\text { gestação e fatores } \\
\text { associados: estudo } \\
\text { longitudinal. }\end{array}$ & (LIMA et al., 2017) & $\begin{array}{lr}\text { Identificar } & \text { a } \\
\text { frequência } & \text { de } \\
\text { sintomas } & \\
\text { depressivos } & \text { no } \\
\text { decorrer } & \text { da } \\
\text { gestação. } & \end{array}$ & $\begin{array}{l}\text { Estudo } \\
\text { longitudinal. }\end{array}$ & $\begin{array}{lr}\text { Escala } & \text { de } \\
\text { depressão } & \text { pós } \\
\text { parto } & \text { de } \\
\text { Edinburgh. } & \\
\text { (Edinburgh } & \\
\text { Postnatal } & \\
\text { Depression } & \\
\text { Scale) } & \end{array}$ \\
\hline $\begin{array}{lr}\text { Identificação } & \text { de } \\
\text { sintomas } & \\
\text { depressivos no } & \text { noriodo pós-parto } \\
\text { em ranes } & \text { mães } \\
\text { adolescentes. }\end{array}$ & $\begin{array}{l}\text { (CARDILLO et al., } \\
2016)\end{array}$ & $\begin{array}{l}\text { Determinar } \\
\text { prevalência } \\
\text { sintomas de } \\
\text { depressivos em } \\
\text { mães adolescentes } \\
\text { e caracteriza-las } \\
\text { quanto aos } \\
\text { aspectos } \\
\text { sociodemográficos, } \\
\text { comportamentais e } \\
\text { de saúde mental. }\end{array}$ & $\begin{array}{l}\text { Estudo } \\
\text { observacional, } \\
\text { descritivo e } \\
\text { transversal. }\end{array}$ & $\begin{array}{l}\text { Escala de } \\
\text { depressão pós- } \\
\text { parto de } \\
\text { Edinburgh } \\
\text { (Edinburgh } \\
\text { Postnatal } \\
\text { Depression Scale } \\
\text { E Escala de } \\
\text { avaliação para } \\
\text { depressão de } \\
\text { Hamilton. }\end{array}$ \\
\hline
\end{tabular}

Fonte: elaboração própria.

Quadro 4 - Caracterização da amostra (artigos incluídos na revisão narrativa) baseada na Escala de avaliação para depressão Hamilton

\begin{tabular}{|c|c|c|c|c|}
\hline Título & $\begin{array}{l}\text { Autores e ano } \\
\text { de publicação }\end{array}$ & $\begin{array}{c}\text { Principal (ais) } \\
\text { objetivo(s) }\end{array}$ & $\begin{array}{l}\text { Tipo de } \\
\text { estudo }\end{array}$ & $\begin{array}{c}\text { Escala de } \\
\text { avaliação para } \\
\text { depressão de } \\
\text { Hamilton }\end{array}$ \\
\hline $\begin{array}{l}\text { Identificação de } \\
\text { sintomas } \\
\text { depressivos no } \\
\text { período pós-parto } \\
\text { em mães } \\
\text { adolescentes. }\end{array}$ & $\begin{array}{l}\text { (CARDILLO et al., } \\
2016)\end{array}$ & $\begin{array}{l}\text { Determinar a } \\
\text { prevalência de } \\
\text { sintomas } \\
\text { depressivos em } \\
\text { mães adolescentes } \\
\text { e caracteriza-las } \\
\text { quanto aos } \\
\text { aspectos sociodemográficos, } \\
\text { comportamentais e } \\
\text { de saúde mental. }\end{array}$ & $\begin{array}{l}\text { Estudo } \\
\text { observacional, } \\
\text { descritivo e } \\
\text { transversal. }\end{array}$ & $\begin{array}{lr}\text { Escala } & \text { de } \\
\text { depressão pós- } & \text { de } \\
\text { parto } & \text { Edinburgh } \\
\text { (Edinburgh } & \\
\text { Postnatal } \\
\text { Depression Scale } \\
\text { E Escala de } \\
\text { avaliação para } \\
\text { depressão de } \\
\text { Hamilton. }\end{array}$ \\
\hline
\end{tabular}


Quadro 4 - Caracterização da amostra (artigos incluídos na revisão narrativa) baseada na Escala de avaliação para depressão Hamilton, continuação

\begin{tabular}{|c|c|c|c|c|}
\hline $\begin{array}{l}\text { Sintomas de } \\
\text { depressão e fatores } \\
\text { intervenientes entre } \\
\text { enfermeiros de } \\
\text { serviço hospitalar } \\
\text { de emergência. }\end{array}$ & $\begin{array}{l}\text { (OLIVEIRA; } \\
\text { MAZZAIA; } \\
\text { MARCOLAN, } \\
2014)\end{array}$ & $\begin{array}{l}\text { Verificar } r \\
\text { enfermeiros do } \\
\text { serviço hospitalar } \\
\text { de emergência } \\
\text { apresentavam } \\
\text { sintomas } \\
\text { depressivos, } \\
\text { identificar fatores } \\
\text { intervenientes e } \\
\text { analisar percepção } \\
\text { sobre o sofrimento } \\
\text { psíquico e influência } \\
\text { na assistência } \\
\text { prestada. }\end{array}$ & $\begin{array}{l}\text { Estudo } \\
\text { transversal, } \\
\text { quantitativo. }\end{array}$ & $\begin{array}{lr}\text { Inventario } & \text { de } \\
\text { depressão } & \text { Beck, } \\
\text { Escala } & \text { de } \\
\text { avaliação } & \text { de } \\
\text { depressão } & \\
\text { Hamilton } & \text { e } \\
\text { Montgomery- } & \\
\text { Asberg } & \\
\text { Depression } & \\
\text { Rating Scale. }\end{array}$ \\
\hline
\end{tabular}

Fonte: elaboração própria.

Quadro 5 - Caracterização da amostra (artigos incluídos na revisão narrativa) baseada na Escala de avaliação para depressão de Montgomery - Asberg Depression Rating Scale

\begin{tabular}{|c|c|c|c|c|}
\hline Título & $\begin{array}{l}\text { Autores e ano } \\
\text { de publicação }\end{array}$ & $\begin{array}{c}\text { Principal (ais) } \\
\text { objetivo(s) }\end{array}$ & Tipo de estudo & $\begin{array}{c}\text { Escala de } \\
\text { avaliação para } \\
\text { depressão de } \\
\text { Montgomery- } \\
\text { Asberg } \\
\text { Depression } \\
\text { Rating Scale }\end{array}$ \\
\hline $\begin{array}{l}\text { Sintomas de } \\
\text { depressão } \\
\text { fatores } \\
\text { intervenientes } \\
\text { entre enfermeiros } \\
\text { de serviço } \\
\text { hospitalar de } \\
\text { emergência. }\end{array}$ & $\begin{array}{l}\text { (OLIVEIRA; } \\
\text { MAZZAIA; } \\
\text { MARCOLAN, } \\
\text { 2014) }\end{array}$ & $\begin{array}{l}\text { Verificar se } \\
\text { enfermeiros do } \\
\text { serviço hospitalar } \\
\text { de emergência } \\
\text { apresentavam } \\
\text { sintomas } \\
\text { depressivos, } \\
\text { identificar fatores } \\
\text { intervenientes e } \\
\text { analisar } \\
\text { percepção sobre } \\
\text { o sofrimento } \\
\text { psíquico ro } \\
\text { influência na } \\
\text { assistência } \\
\text { prestada. }\end{array}$ & $\begin{array}{l}\text { Estudo } \\
\text { transversal, } \\
\text { quantitativo. }\end{array}$ & $\begin{array}{lr}\text { Inventario } & \text { de } \\
\text { depressão } & \text { Beck, } \\
\text { Escala } & \text { de } \\
\text { avaliação } & \text { de } \\
\text { depressão } & \\
\text { Hamilton } & \text { e } \\
\text { Montgomery- } & \\
\text { Asberg } & \\
\text { Depression } & \\
\text { Rating Scale. } & \end{array}$ \\
\hline
\end{tabular}

Fonte: elaboração própria. 
Quadro 6 - Caracterização da amostra (artigos incluídos na revisão narrativa) baseada na Escala hospitalar de ansiedade e depressão

\begin{tabular}{|c|c|c|c|c|}
\hline Título & $\begin{array}{l}\text { Autores e ano } \\
\text { de publicação }\end{array}$ & $\begin{array}{c}\text { Principal (ais) } \\
\text { objetivo(s) }\end{array}$ & Tipo de estudo & $\begin{array}{c}\text { Escala } \\
\text { hospitalar de } \\
\text { ansiedade e } \\
\text { depressão }\end{array}$ \\
\hline $\begin{array}{l}\text { Associação entre } \\
\text { ansiedade } \quad \text { e } \\
\text { depressão e a } \\
\text { qualidade de vida } \\
\text { de pacientes } \\
\text { renais crônicos } \\
\text { em hemodiálise. }\end{array}$ & $\begin{array}{l}\text { (OTTAVIANE et } \\
\text { al., 2016) }\end{array}$ & $\begin{array}{l}\text { Analisar a relação } \\
\text { entre a ansiedade } \\
\text { e depressão e } \\
\text { qualidade de vida } \\
\text { de pacientes } \\
\text { renais crônicos } \\
\text { em tratamento } \\
\text { hemodialítico. }\end{array}$ & $\begin{array}{l}\text { Estudo } \\
\text { correlacional, } \\
\text { transversal, } \\
\text { quantitativo. }\end{array}$ & $\begin{array}{l}\text { Escala hospitalar } \\
\text { de ansiedade e } \\
\text { depressão } \\
\text { (Hospital anxiety } \\
\text { and depression } \\
\text { scale- HADS) }\end{array}$ \\
\hline $\begin{array}{l}\text { Prevalência de } \\
\text { síndrome } \\
\text { metabólica entre } \\
\text { trabalhadores de } \\
\text { enfermagem e } \\
\text { associação com } \\
\text { estresse } \\
\text { ocupacional, } \\
\text { ansiedade } \\
\text { depressão. }\end{array}$ & $\begin{array}{l}\text { (RIBEIRO et al., } \\
2015)\end{array}$ & $\begin{array}{lr}\text { Identificar } & \text { a } \\
\text { prevalência } & \text { da } \\
\text { Síndrome } & \\
\text { Metabólica entre } \\
\text { trabalhadores de } \\
\text { enfermagem e } \\
\text { sua associação } \\
\text { com estresse } \\
\text { ocupacional, } \\
\text { ansiedade } \\
\text { depressão. }\end{array}$ & $\begin{array}{l}\text { Estudo descritivo, } \\
\text { correlacional } \\
\text { transversal. }\end{array}$ & $\begin{array}{l}\text { Escala hospitalar } \\
\text { de ansiedade e } \\
\text { depressão. }\end{array}$ \\
\hline $\begin{array}{l}\text { Auto eficácia e } \\
\text { morbidade } \\
\text { psicológica no } \\
\text { pós-operatório de } \\
\text { prostatectómia } \\
\text { radical }\end{array}$ & $\begin{array}{l}\text { (MATA et al., } \\
2015)\end{array}$ & $\begin{array}{l}\text { Avaliar a auto } \\
\text { eficácia geral e } \\
\text { percebida, a } \\
\text { morbidade } \\
\text { psicológica e } \\
\text { conhecimento } \\
\text { sobre cuidados } \\
\text { pós-operatórios } \\
\text { de pacientes } \\
\text { submetidos à } \\
\text { prostatectomia } \\
\text { radical. }\end{array}$ & $\begin{array}{l}\text { Estudo descritivo, } \\
\text { transversal. }\end{array}$ & $\begin{array}{l}\text { Escala hospitalar } \\
\text { de ansiedade e } \\
\text { depressão. } \\
\text { (Hospital anxiety } \\
\text { and depression } \\
\text { scale- HADS) }\end{array}$ \\
\hline
\end{tabular}

Fonte: elaboração própria. 
Quadro 7 - Caracterização da amostra (artigos incluídos na revisão narrativa) baseada na Escala short-care que integra o instrumento de avaliação multidimensional BOAS

\begin{tabular}{|c|c|c|c|c|}
\hline Título & $\begin{array}{l}\text { Autores e ano } \\
\text { de publicação }\end{array}$ & $\begin{array}{l}\text { Principal (ais) } \\
\text { objetivo(s) }\end{array}$ & $\begin{array}{l}\text { Tipo de } \\
\text { estudo }\end{array}$ & $\begin{array}{l}\text { Escala short-care } \\
\text { que integra o } \\
\text { instrumento de } \\
\text { avaliação } \\
\text { multidimensional } \\
\text { BOAS }\end{array}$ \\
\hline $\begin{array}{lr}\text { Prevalência } & \text { de } \\
\text { sintomas } & \\
\text { depressivos } & \text { e } \\
\text { sinais } & \text { de } \\
\text { demência } & \text { em } \\
\text { idosos } & \text { na } \\
\text { comunidade. } & \end{array}$ & $\begin{array}{l}\text { (LENTSCK et al., } \\
\text { 2015) }\end{array}$ & $\begin{array}{l}\text { Analisar a } \\
\text { prevalência de } \\
\text { sintomas } \\
\text { depressivos, sinais } \\
\text { de demência e } \\
\text { fatores associados } \\
\text { em idosos } \\
\text { residentes em } \\
\text { município do } \\
\text { sul do Brasil. }\end{array}$ & $\begin{array}{l}\text { Estudo } \\
\text { transversal. }\end{array}$ & $\begin{array}{l}\text { Escala Short-Care } \\
\text { (avaliativa de saúde } \\
\text { mental), constante } \\
\text { no instrumento de } \\
\text { avaliação } \\
\text { multidimensional } \\
\text { BOAS (Brazil Old } \\
\text { Age Schedule). }\end{array}$ \\
\hline $\begin{array}{lr}\text { Sintomas } & \\
\text { depressivos } & \text { em } \\
\text { idosos: } & \\
\text { comparação } & \text { entre } \\
\text { residentes } & \text { em } \\
\text { condomínio } & \\
\text { especifica } & \text { para } \\
\text { idosos e } & \text { na } \\
\text { comunidade. } & \end{array}$ & $\begin{array}{l}\text { (TESTON; } \\
\text { CARREIRA; } \\
\text { MARCON, 2014) }\end{array}$ & $\begin{array}{lr}\text { Comparar } & \text { os } \\
\text { sintomas } & \text { de } \\
\text { depressão } & \text { entre } \\
\text { residentes em } & \text { um } \\
\text { Condomínio } & \text { para } \\
\text { idosos e } & \text { na } \\
\text { comunidade. } & \end{array}$ & $\begin{array}{l}\text { Estudo } \\
\text { quantitativo. }\end{array}$ & $\begin{array}{l}\text { Escala Short-Care } \\
\text { (avaliativa de saúde } \\
\text { mental), constante } \\
\text { no instrumento de } \\
\text { avaliação } \\
\text { multidimensional } \\
\text { BOAS (Brazil Old } \\
\text { Age Schedule). }\end{array}$ \\
\hline
\end{tabular}

Fonte: elaboração própria.

No presente estudo foram identificados sete (07) instrumentos de avaliação de depressão utilizados na prática clínica de enfermagem. São eles: Escala de depressão geriátrica de Yesavage, Inventário de depressão de Beck, Escala de depressão de Edimburgo, Escala de avaliação para depressão de Hamilton, Montgomery-Asberg Depression Rating Scale, Escala hospitalar de ansiedade e depressão, bem como a escala short-care, que integra o instrumento de avaliação multidimensional BOAS (Brazil Old Age Schedule). (FREIRE et al, 2018; MONTEIRO et al, 2013; CARDILLO et al, 2016; OLIVEIRA; MAZZAIA; MARCOLAN, 2014)

Quanto ao público com quem os instrumentos foram aplicados nos estudos integrantes da amostra, teve-se bastante diversificação: idosos, profissionais de saúde, pacientes adultos com problemas clínicos específicos, acadêmicos de Enfermagem, gestantes e puérperas. (FERREIRA et al, 2013; MONTEIRO et al, 2013; MOREIRA; FUREGATO, 2013; CARDILLO et al., 2016)

É importante ressaltar que o maior público no qual foi utilizado algum instrumento para avaliar depressão foi em pessoas idosas e profissionais da área de 
saúde, ambos com nove artigos e diferentes instrumentos utilizados. Instrumento esses do qual mais se destaca como escala de depressão geriátrica e inventário de depressão de Beck. (LEAL et al., 2014; RODRIGUES et al., 2014; GOMES; OLIVEIRA, 2013)

No entanto inventario de depressão de Beck não pode ser utilizado por enfermeiros e sim por psicólogos por se tratar de um instrumento diagnóstico da área de psicologia. Embora seja um instrumento bastante utilizado em pesquisas de enfermeiros teoricamente ele não deveria ser utilizado pelos mesmos (PARANHOS; ARGIMON; WERLANG, 2010; GANDIN et al., 2007)

Outro fator relevante a este instrumento é que é necessário comprar a escala de uma editora nacional de psicologia: A casa do psicólogo. Além disso essa editora tem um manual de utilização desse instrumento do qual também deve ser comprado e lido para que os psicólogos possam aplica-la (PARANHOS; ARGIMON; WERLANG, 2010; GANDIN et al., 2007)

No público idoso foram usados dois instrumentos para avaliar depressão dentre eles escala de depressão geriátrica e short-care, que integra o instrumento de avaliação multidimensional BOAS (Brazil Old Age Schedule) a mais utilizada foi a escala de depressão geriátrica encontrada em sete dentre os nove artigos. Em muitos desses estudos os idosos que apresentam alguma característica relacionada à depressão em sua maioria são idosos institucionalizados e de sexo feminino (GUTHS, et al., 2017).

Para profissionais da área de saúde foram utilizados quatro instrumentos: inventário de depressão de Beck, escala de avaliação de depressão Hamilton, escala Montgomery-Asberg (Depression Rating Scale) e escala hospitalar de ansiedade e depressão, dentre essas citadas a mais utilizada foi o inventario de depressão de Beck usado em oito dentre os nove artigos.

Muitos destes profissionais tendem a apresentar alguma característica relacionada a depressão devido a sobrecarga de trabalho, desgaste, renumeração insatisfatória e problemas familiares em meio a outros aspectos (OLIVEIRA; MAZZAIA; MARCOLAN, 2015)

Adultos com problemas clínicos específicos foram encontrados em três artigos dos quais foram utilizados dois instrumentos, um em inventário de depressão de Beck e dois na escala hospitalar de ansiedade e depressão. As patologias 
relatadas nos estudos associadas à depressão foram hipertensão, pacientes renais crônicos em hemodiálise e pós-operatório de prostatectomia radical.

Acadêmicos de enfermagem revelaram-se apenas dois artigos, utilizando o instrumento inventário de depressão de Beck, da qual em um dos estudos foi usada a escala em 91 alunos do $1^{\circ}$ ao $7^{\circ}$ semestre, a pesquisa ainda revelou a predominância do sexo feminino representado por 85 pessoas das 91(CAMARGO; SOUSA; OLIVEIRA, 2014).

Em gestantes e puérperas o público foi bem menor, da qual em gestante teve apenas um artigo do qual o instrumento foi a escala de depressão pós-parto de Edimburgo e em puérpera dois artigos do qual os instrumentos foram escala de depressão pós-parto de Edimburgo e escala de avaliação para depressão de Hamilton (CARDILLO et al., 2016; LIMA et al., 2017).

O quadro 2, abaixo, mostra os instrumentos de avaliação de depressão identificados na presente revisão narrativa, bem como as informações sobre: país de origem do instrumento e ano de construção, validação para uso no Brasil (ano e autores), características psicométricas (validade e confiabilidade) com amostras brasileiras, número de itens do instrumento e tempo médio para sua administração.

Quadro 8 - Caracterização da amostra (artigos incluídos na revisão narrativa) conforme descrição

\begin{tabular}{|c|c|c|c|c|}
\hline $\begin{array}{l}\text { Instrumento de } \\
\text { avaliação da } \\
\text { depressão }\end{array}$ & $\begin{array}{c}\text { País de } \\
\text { origem do } \\
\text { instrumento e } \\
\text { ano }\end{array}$ & $\begin{array}{c}\text { Validação } \\
\text { para uso no } \\
\text { Brasil. (ano e } \\
\text { autores) }\end{array}$ & $\begin{array}{c}\text { Características } \\
\text { de validade e } \\
\text { confiabilidade } \\
\text { do instrumento } \\
\text { com amostras } \\
\text { brasileiras }\end{array}$ & $\begin{array}{c}\text { Numero de } \\
\text { itens do } \\
\text { instrumento e } \\
\text { aplicação }\end{array}$ \\
\hline $\begin{array}{l}\text { Escala de depressão } \\
\text { geriátrica de Yesavage. }\end{array}$ & $\begin{array}{l}\text { Estados } \text { Unidos } \\
\text { da América, } \\
\text { 1983. }\end{array}$ & $\begin{array}{l}\text { ALMEIDA; } \\
\text { ALMEIDA, } \\
1999 .\end{array}$ & $\begin{array}{l}\text { No ponto de corte } \\
5 / 6, \text { sensibilidade } \\
\text { de } 85,4 \% \text { e a } \\
\text { especificidade de } \\
73,9 \% \text { Já no } \\
\text { ponto de corte } \\
6 / 7, \text { a } \\
\text { sensibilidade foi } \\
\text { de } 84,8 \% \text { e a } \\
\text { especificidade de } \\
67,7 \% \text {, mostrou- } \\
\text { se confiável e } \\
\text { válida em um } \\
\text { ambulatório un } \\
\text { especializado. }\end{array}$ & 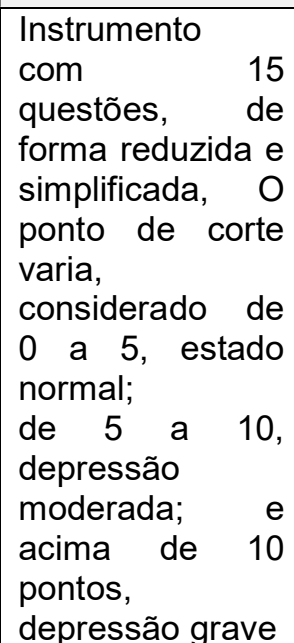 \\
\hline
\end{tabular}


Quadro 8 - Caracterização da amostra (artigos incluídos na revisão narrativa) conforme descrição, continuação

\begin{tabular}{|c|c|c|c|c|}
\hline $\begin{array}{l}\text { Escala de depressão } \\
\text { pós-parto de Edinburgh. } \\
\text { (EPDS) }\end{array}$ & $\begin{array}{l}\text { Reino Unido, } \\
1987 .\end{array}$ & $\begin{array}{l}\text { SANTOS et al., } \\
2007 .\end{array}$ & 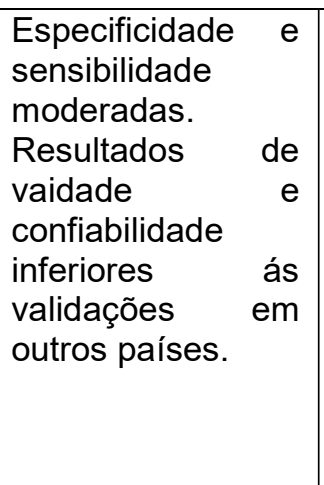 & $\begin{array}{l}\text { Dez itens, } \\
\text { autoaplicável, } \\
\text { possuem quatro } \\
\text { opções de } \\
\text { respostas, } \\
\text { pontuadas de } 0 \\
\text { a } 3 \text { de acordo } \\
\text { com a ausência, } \\
\text { presença } \\
\text { e intensidade } \\
\text { dos sintomas de } \\
\text { depressão. }\end{array}$ \\
\hline $\begin{array}{l}\text { Escala Short-Care } \\
\text { (avaliativa de saúde } \\
\text { mental), constante no } \\
\text { instrumento } \\
\text { avaliação } \\
\text { multidimensional BOAS } \\
\text { (Brazil Old Age } \\
\text { Schedule). }\end{array}$ & $\begin{array}{l}\text { Inglaterra, em } \\
1986\end{array}$ & $\begin{array}{l}\text { TESTON; } \\
\text { CARREIRA; } \\
\text { MARCON, } \\
2014 .\end{array}$ & $\begin{array}{l}\text { Considera-se } \\
\text { como caso de } \\
\text { depressão valor } \\
\text { igual ou superior a } \\
\text { oito pontos, pois } \\
\text { este foi o ponto de } \\
\text { corte que melhor } \\
\text { propiciou } \\
\text { equilibrio entre } \\
\text { sensibilidade e } \\
\text { especificidade } \\
\text { para se definir } \\
\text { possíveis casos } \\
\text { de depressão }\end{array}$ & $\begin{array}{l}\text { É constituído de } \\
\text { nove seções que } \\
\text { objetivam coletar } \\
\text { informações } \\
\text { referentes as } \\
\text { principais } \\
\text { características, } \\
\text { necessidades e } \\
\text { problemas da } \\
\text { população idosa. }\end{array}$ \\
\hline $\begin{array}{l}\text { Escala de avaliação } \\
\text { para depressão de } \\
\text { Hamilton (Hamilton } \\
\text { depression rating scale } \\
\text { HAM-D) }\end{array}$ & Inglaterra 1960. & $\begin{array}{l}\text { FREIRE et al, } \\
2014 .\end{array}$ & $\begin{array}{l}\text { Alta sensibilidade } \\
\text { e especificidade } \\
\text { de } 90 \text { e } 91 \% \text {, } \\
\text { respectivamente. } \\
\text { Da qual evidencia } \\
\text { características } \\
\text { favoráveis para a } \\
\text { utilização da } \\
\text { escala no Brasil. }\end{array}$ & $\begin{array}{l}\text { É composta por } \\
17 \text { itens, os } \\
\text { quais, } \\
\text { podem } \\
\text { pontuados numa } \\
\text { escala Likert que } \\
\text { varia entre } 0 \\
\text { a } 2 \text { ou } 0 \text { a } 4, \\
\text { conforme a } \\
\text { intensidade do } \\
\text { sintoma }\end{array}$ \\
\hline $\begin{array}{l}\text { Montgomery-Asberg } \\
\text { Depression } \quad \text { Rating } \\
\text { Scale }\end{array}$ & $\begin{array}{l}\text { Desenvolvida } \\
\text { em } 1979\end{array}$ & $\begin{array}{l}\text { CANO; } \\
\text { GOMEZ; } \\
\text { RONDRES } \\
2016 .\end{array}$ & $\begin{array}{l}\text { A confiabilidade } \\
\text { da nova escala de } \\
\text { depressão foi } \\
\text { alta. }\end{array}$ & $\begin{array}{l}\text { Consiste em dez } \\
\text { questões que } \\
\text { avaliam } \\
\text { aspectos } \\
\text { biológicos, } \\
\text { afetivos } \\
\text { comportamentais } \\
\text { que podem são } \\
\text { pontuados até o } \\
\text { máximo de seis. }\end{array}$ \\
\hline $\begin{array}{l}\text { Hospital Anxiety and } \\
\text { Depression Scale - } \\
\text { HADS }\end{array}$ & Noruega, 1983 & $\begin{array}{l}\text { BOTEGA et al., } \\
1995 .\end{array}$ & 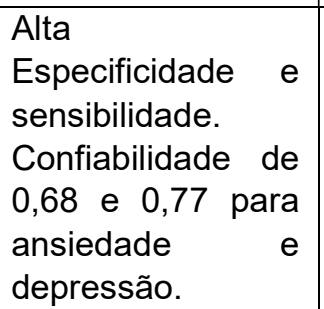 & $\begin{array}{l}14 \text { questões de } \\
\text { múltipla escolha } \\
\text { em duas sub } \\
\text { escalas } \\
\text { ansiedade/ } \\
\text { depressão sete } \\
\text { itens cada) }\end{array}$ \\
\hline
\end{tabular}

Fonte: Elaboração própria. 
Escala de depressão geriátrica de Yesavage é utilizada para rastreamento de sintomas depressivos assim como alterações de humor em idosos. É importante ressaltar que a escala geriátrica de depressão com 15 itens é uma versão reduzida da escala original elaborada por Sheikh e Yesavage.

A versão reduzida é muito utilizada para rastreamento dos transtornos de humor em ambulatórios gerais assim como outros locais não especializados porque o tempo de administração se torna menor (PARADELA; LOURENÇO; VERAS, 2005).

A escala de depressão de Edimburgo é um instrumento autoaplicável composto por dez enunciados no qual vai auxiliar abrangendo os seguintes sintomas, perda de prazer, alterações no sono, humor deprimido, ideias suicidas, diminuição do desempenho nas atividades diárias entre outros fatores. É um instrumento de respostas simples podendo ser aplicados por profissionais não especializados em saúde mental, podendo ser utilizada no pós-parto assim como durante a gestação (LIMA et al, 2017).

A escala de Hamilton foi criada por Max Hamilton em 1960 para ser utilizada para pacientes que tinham diagnósticos de transtornos afetivos depressivos com ênfase nisso esse instrumento serve para analisar a gravidade dos sintomas depressivos e não sua existência (FREIRE et al, 2014).

Escala de depressão Montgomery-Asberg é composta por dez itens da qual em alguns aspectos se torna mais sensível que a de Hamilton por discriminar pacientes que estão respondendo ao tratamento com antidepressivos (OLIVEIRA; MAZZAIA; MARCOLAN, 2014).

Uma característica importante da escala hospitalar de ansiedade e depressão é que como já cita no nome ela é dividida em duas sub escalas da qual uma avalia a depressão e a outa ansiedade, contem 14 questões da qual sete é para cada sub escala cada questão de múltipla escolha possui quatro opções ( MATA et al, 2015).

A escala short-care, que integra o instrumento de avaliação multidimensional BOAS (Brazil Old Age Schedule) é um instrumento dividido em nove sessões da qual abrange aspectos de vida do idoso assim como as atividades de vida diária, problemas financeiros, interação social entre outros. A versão validada para português já analisa as alterações relacionado aos sintomas de depressão e 
demência assim como outros aspectos tipo cefaleia, sono prejudicado (LENTSCK et al, 2016).

Tais instrumentos são bastante essenciais para a prática clínica de enfermagem pois proporcionam um rastreio para um diagnostico mais preciso, facilitando a assistência prestada pelo profissional. Diante do que foi visto na revisão nota-se que é necessário construir novos instrumentos e que os mesmos sejam validados com públicos específicos. 


\section{CONCLUSÕES}

De acordo com a literatura científica nacional, há alguns instrumentos de avaliação da depressão que podem ser utilizados por enfermeiros em sua prática clínica.

Dentre os quais, citam-se: Escala de depressão geriátrica de Yesavage, Escala de depressão de Edimburgo, Escala de avaliação para depressão de Hamilton, Montgomery-Asberg Depression Rating Scale, Escala hospitalar de ansiedade e depressão, bem como a escala short-care, que integra o instrumento de avaliação multidimensional BOAS (Brazil Old Age Schedule).

Verificou-se que, de acordo com o público-alvo, há instrumentos específicos que são mais recomendados para utilização nos cenários assistenciais.

Tais instrumentos são de fácil aplicação com perguntas de respostas simples proporcionando um apoio no rastreio da avaliação de depressão. O enfermeiro tem um papel fundamental no conhecimento e aplicação dos instrumentos, pois o mesmo vai poder agir na promoção de saúde prevenindo possíveis fatores causais relacionados à depressão.

Entende se que na prática clínica do enfermeiro há vários instrumentos que possibilitam um trabalho mais intenso proporcionando melhores resultados para o profissional e para o paciente, pois o mesmo estará ciente sobre possíveis fatores de riscos que podem prejudicar a saúde, facilitando seu trabalho para uma melhor elaboração de estratégias em saúde.

O enfermeiro é a pessoa que possui maior vinculo com o paciente passando segurança orientando e mostrando que de fato a depressão é uma doença séria e que precisa de cuidados, é importante demostrar que depressão não é tristeza ela vai muito, além disso, e se não for diagnosticada e tratada de maneira efetiva pode levar a morte.

Também é possível perceber a necessidade de mais publicações sobre o tema, o que iria ajudar na atualização e em novas descobertas para muitos profissionais.

É importante o conhecimento sobre esses instrumentos porque são eles que ajudam a obter de maneira mais eficiente um rastreio sobre depressão, no sentindo de encaminhamentos e elaboração de intervenções de enfermagem. 


\section{REFERÊNCIAS}

BOTEGA, Neury J. Transtornos do humor em enfermaria de clínica médica e validação de escala de medida (HAD) de ansiedade e depressão. Revista Saúde Pública, São Paulo, v. 29, n. 5, p. 359-363, out. 1995. Disponível em: $<$ http://www.scielo.br/scielo.php?script=sci_arttext\&pid=S0034-

$89101995000500004 \&$ Ing=en\&nrm=iso>. Acesso em: 22 out. 2018.

CAMARGO, R. M.; et al. Prevalência de casos de depressão em acadêmicos de enfermagem em uma instituição de ensino de Brasília. Revista Mineira de enfermagem, Minas Gerais, 2014 abri/jun 18 (2) 392-397.

CANO, Juan Fernando; RESTREPO, Carlos Gomez; RONDÓN, Martín. Validación en Colombia del instrumento para evaluación de la depresión Montgomery-Åsberg Depression Rating Scale (MADRS). Revista Colombiana Psiquiatra, Bogotá, v. 45, n. 3, p. 146-155, jul. 2016. Disponível em: <encurtador.com.br/hkqF7>. Acesso em: 22 out. 2018.

CARDILLO, V. A.; et al. Identificação de sintomas depressivos no período pós-parto em mães adolescentes. Revista Eletrônica de Enfermagem, Goiânia, v. 18, mar. 2016, p. 1518-1944. Disponível em: <https://revistas.ufg.br/fen/article/view/32728>. Acesso em: 07 out. 2018.

FERREIRA, P. C. S.; et al. Características sociodemográficas e hábitos de vida de idosos com e sem indicativo de depressão. Revista Eletrônica de Enfermagem, Goiânia, v. 15, n. 1, p. 197-204, mar. 2013. ISSN 1518-1944. Disponível em: <https://revistas.ufg.br/fen/article/view/16643>. Acesso em: 07 out. 2018.

FREIRE, H. S. S.; et al. Aplicação da escala de depressão geriátrica de yesavage em instituições de longa permanência. Revista Nursing, 2018; 21 (237) 2030-2031.

FREIRE, M. Á.; et al. Escala Hamilton: estudo das características psicométricas em uma amostra do sul do Brasil. J. bras. psiquiatra, Rio de Janeiro v. 63, n. 4, p. 281-289. Disponível em: <encurtador.com.br/aenEN>. Acesso em: 07 out. 2018.

GANDINI, R. C.; et al. Inventário de Depressão de Beck - BDI: validação fatorial para mulheres com câncer. Psico-USF (Impresso), Itatiba, v. 12, n. 1, p. 23-31, Disponível em: <encurtador.com.br/pANV7>. Acesso em: 07 out. 2018.

GOMES, R. K.; OLIVEIRA, V. B. Depressão, ansiedade e suporte social em profissionais de enfermagem. Boletim de psicologia, São Paulo, v. 63, n. 138, p. 23-33. Disponível em <encurtador.com.br/uHJT2>. Acessos em 07 out. 2018.

GUTHS, J. F. S.; et al. Sociodemographic profile, family aspects, perception of health, functional capacity and depression in institutionalized elderly persons from the north coastal region of Rio Grande do Sul, Brazil. R Revista Brasileira de Geriatria e Gerontologia, Rio de Janeiro, v. 20, n. 2, p. 175-185. Disponível em: <encurtador.com.br/JKV69>. Acesso em: 07 out. 2018.

LEAL, M. C. C.; et al. Prevalência de sintomatologia depressiva e fatores associados entre idosos institucionalizados. Acta paul. enfermagem, São Paulo, v. 27, n. 3, p. 208-214. Disponível em: <https://goo.gl/dm5wEH>. Acesso em: 07 out. 2018. 
LENTSCK, M. H.; et al. Prevalência de sintomas depressivos e sinais de demência em idosos na comunidade. Revista Eletrônica de Enfermagem, Goiânia, v. 17, n 6, p. 1518-1944. Disponível em: <https://revistas.ufg.br/fen/article/view/34261>. Acesso em: 07 out. 2018.

LIMA, A. M. P.; et al. Depressão em idosos: uma revisão sistemática da literatura. Revista de Epidemiologia e Controle de Infecção, Santa Cruz do Sul, v. 6 , n. 2, p. 96-103, abr. 2016, p. 2238-3360. Disponível em: $<$ https://online.unisc.br/seer/index.php/epidemiologia/article/view/6427>. Acesso em: 15 out. 2018.

LIMA, M. O. P.; et al. Sintomas depressivos na gestação e fatores associados: estudo longitudinal. Acta paulista enfermagem, São Paulo, v. 30, n. 1, p. 3946, jan. 2017. Disponível em < https://goo.gl/pFz6Wq >. Acesso em: 01 set. 2018.

LOPES, J. M.; et al. Associação da depressão com as características sociodemográficas: qualidade do sono e hábitos de vida em idosos do Nordeste brasileiro: estudo seccional de base populacional. Revista Brasileira de Geriatria e Gerontologia, Rio de Janeiro, v. 18, n. 3, p. 521-531. Disponível em: <http://www.scielo.br/scielo.php?script=sci_arttext\&pid=S1809$98232015000300521 \&$ Ing=en\&nrm=iso>. Acesso em: 07 out. 2018.

MACHADO, D. A.; et al. Cognitive changes in nurses working in intensive care units. Revista Brasileira de Enfermagem, Brasília, v. 71, n. 1, p. 73-79 Disponível em: $<$ http://www.scielo.br/scielo.php?script=sci_arttext\&pid=S0034-

$71672018000100073 \&$ Ing=en\&nrm=iso>. Acesso em: 07 out. 2018.

MATA, L. R. F.; et al. Autoeficácia pós-operatória e morbidade psicológica na prostatectomia radical. Revista Latino-Americana de Enfermagem, Ribeirão Preto, v. 23 , n. 5 , p. 806-813, out. 2015. Disponível em: <https://goo.gl/uCt48E>. Acesso em: 07 out.

MELO, B. R. S.; et al. Avaliação cognitiva e funcional de idosos usuários do serviço público de saúde. Escola Anna Nery, Rio de Janeiro, v. 21, n. 4, 2017. Disponível em: <https://goo.gl/juqdEH>. Acesso em: 07 out. 2018.

MONTEIRO, J. K.; et al. Adoecimento psíquico de trabalhadores de unidades de terapia intensiva. Psicologia: Ciência e Profissão, Brasília, v. 33, n. 2, p. 366-379. Disponível em: <https://goo.gl/bbv5Vq>. Acesso em: 07 out. 2018.

MONTOVANI, M. F.; et al. Depressão e qualidade de vida em adultos com hipertensão. Cogitare enfermagem, Paraná, v. 22, n. 3, 2017. Disponível em: $<$ https://revistas.ufpr.br/cogitare/article/view/51630/pdf_en>. Acesso em: 07 out. 2018.

MOREIRA, D. P.; FUREGATO, A. R. F. Estresse e depressão entre estudantes do último semestre em dois cursos de enfermagem. Revista LatinoAmericana Enfermagem, Ribeirão Preto, v. 21, p. 155-162, fevereiro de 2013. Disponível em: <http://www.scielo.br/scielo.php?script=sci_arttext\&pid=S0104$11692013000700020 \&$ Ing=en\&nrm=iso>. Acesso em: 07 out. $2 \overline{018 .}$ 
NOBREGA, I. R. A. P.; et al. Fatores associados à depressão em idosos institucionalizados: revisão integrativa. Saúde debate, Rio de Janeiro, v. 39, n. 105, p. 536-550, junho 2015. Disponível em: <https://goo.gl/E4t81v>. Acesso em: 15 out. 2018.

OLIVEIRA, F. P.; et al. Sintomas de depressão e fatores intervenientes entre enfermeiros de serviço hospitalar de emergência. Acta paulista de enfermagem, São Paulo, v. 28, n. 3, p. 209-215, jun. 2015. Disponível em: <http://www.scielo.br/scielo.php?script=sci_arttext\&pid=S0103-

21002015000300209\&lng=pt\&nrm=iso>. Acesso em: 07 out. 2018.

OTTAVIANI, A. C.; et al. Association Between Anxiety and Depression and Quality of life of Chronic Renal Patients on Hemodialysis. Texto contexto - enfermagem, Florianopolis, v. 25, n. 3, 2016. Disponível em: <https://goo.gl/1WLt1Y>. Acesso em: 07 out. 2018.

PARADELA, E. M. P.; LOURENÇO, R. A.; VERAS, R. P. Validação da escala geriátrica em um ambulatório geral. Revista de Saúde pública, São Paulo, v. 39n 6, p. 918-923, Dez 2005. Disponível em: < https://goo.gl/M14MjP>. Acesso em: 07 out. 2018.

PARANHOS, M. E.; at al. Propriedades psicométricas do Inventário de Depressão de Beck-II (BDI-II) em adolescentes. Avaliação psicológica, Porto Alegre, v. 9, n. 3, p. 383-392, dez. 2010. Disponível em: <https://goo.gl/xG31Qa>. Acessos em 16 nov. 2018.

PEREIRA, M. M. A.; et al. Stress burnout e avaliação cognitiva: estudo na classe de enfermagem. Arquivos brasileiros de psicologia, Rio de Janeiro, v. 68, n. 1, p. 7283. Disponível em: <https://www.redalyc.org/html/2290/229046737007/>. Acessos em 16 nov. 2018.

PEREIRA, Rita de Cássia et al. Depressão e bem-estar em individuo idoso com úlcera venosa. Revista Brasileira de Cirurgia Plástica, São Paulo, v. 29, n. 4, p. 567-574, jul. 2014. Disponível em: <https://goo.gl/HWrTdb>. Acesso em: 22 out. 2018.

RIBEIRO, R. P.; et al. Prevalência de Síndrome Metabólica no pessoal de enfermagem e sua associação com estresse ocupacional, ansiedade e depressão. Rev. Latino-Am. Enfermagem, Ribeirão Preto, v. 23, n. 3, p. 435-440, junho de 2015. Disponível em: <https://goo.gl/iXLd8R>. Acesso em 07 out. 2018.

RODRIGUES, L. R.; et al. Perfil sociodemográfico, econômico e de saúde de idosos rurais segundo o indicativo de depressão. Revista Eletrônica de Enfermagem, Goiânia, v. 16, n. 2, p. 278-85, jun. 2014. ISSN 1518-1944. Disponível em: <https://revistas.ufg.br/fen/article/view/20782>. Acesso em: 07 out. 2018.

ROTHER, E. T. Revisão Sistemática X revisão narrativa. Acta Paulista de Enfermagem [online], São Paulo, v. 20, n. 2, p. 0103 - 2100, abril 2007, Disponível em: <http://udg.redalyc.org/articulo.oa?id=3070026613004>. Acesso em: 07 out, 2018. 
SANTOS, I. P.; FUREGATO, A. R. F.; Avaliação da presença de sintomas depressivos entre usuários de plantão noturno em uma unidade de emergência. Revista de enfermagem UERJ, Rio de janeiro, v. 21, n. 3, p. 295-300, julho 2013.

SANTOS, I. S.; et al. Validação da Escala de Depressão Pós-Parto de Edimburgo (EPDS) em uma amostra de mães do Estudo de Coorte de Nascimentos de Pelotas, de 2004. Caderno de Saúde Pública, Rio de Janeiro, v. 23, n. 11, p. 2577-2588, novembro de 2007. Disponível em: <https://goo.gl/iGy7tt>. Acesso em: 16 de nov. de 2018.

SILVA, D. A.; MARCOLAN, J. F.; Desemprego e sofrimento psíquico em enfermeiras. Revista Brasileira de Enfermagem, Brasília, v. 68, n. 5, p. 775-782, out. 2015. Disponível em: <https://goo.gl/spj1i6>. Acesso em: 07 out. 2018.

TESTON, E. F.; CARREIRA, L.; MARCON, S. S.; Sintomas depressivos em idosos: comparação entre residentes em condomínio específico para idoso e na comunidade. Revista Brasileira de Enfermagem, v. 67, n. 3, p. 450-456, jun. 2014. Disponível em <https://goo.gl/nqPYN2>. Acesso em: 07 out. 2018.

VASCONCELOS, E. M.; MARTINO, Milva, M. F.; FRANCA, S. P. S.; Burnout and depressive symptoms in intensive care nurses: relationship analysis. Revista Brasileira de Enfermagem, Brasília, v. 71, n. 1, p. 135-141, Fev. 2018. Available from $<$ http://www.scielo.br/scielo.php?script=sci_arttext\&pid=S0034$71672018000100135 \&$ Ing=en\&nrm=iso >. Acesso em: 07 out. $20 \overline{18 .}$ 